\title{
GENETIC MANIPULATION OF TOMATO (LYCOPERSICON ESCULENTUM) USING WGA GENE THROUGH AGROBACTERIUM MEDIATED TRANSFORMATION
}

\author{
${ }^{1}$ Shantha S.L.*, ${ }^{2}$ Padma, ${ }^{2}$ S.G. Bhat, ${ }^{1}$ Sunil Kumar. C, ${ }^{3}$ Ragavendra Rao. B \\ ${ }^{1}$ Department on Biotechnology, PES Institute of Technology, 100 Feet Ring Road, BSK III \\ Stage, Bangalore Karnataka, India. 560085. \\ ${ }^{2}$ S.G. Bhat Laboratory, BSK III Stage, Bangalore, Karnataka, India. \\ ${ }^{3}$ Dept. of Life Sciences, Sikkim Manipal University, Manipal - 576104, Karnataka, India. \\ *Corresponding address: shanthalingaiah@yahoo.com \\ Received 11September, 2011; Revised 21 December, 2011
}

\begin{abstract}
The major problems faced in the field of Agriculture are loss in crop yield caused by insects, Herbs (weeds), viruses and the pathogens and the pests associated loss is about $14 \%$ of total agricultural production. The use of pesticides has resulted in adverse effect on the beneficial organisms and other plant parts such as leaves, fruits and has reached pollution levels, which has become a major concern for environmentalists. Therefore, products of crops resistant to insects have been the first priority in crop biotechnology. Genetic transformation has led the possibility of transforming crops for enhanced resistance to insects through the use of insect control protein geneWGA (Wheat Germ Agglutinin), a glycoprotein with molecular weight of $34000 \mathrm{Da}$. Toxic effect appears to be mediated through binding of the lectins (WGA) to glycoproteins in the insect leading to the disruption of gut epithelial cells and are believed to be "natures own insecticides". The present study involves preparation of recombinant pGPTV vector having WGA gene, which was transferred to E. coli DH5a basic strain. The recombinant vector was transferred to Agrobacterium tumefaciens strain LBA4404 using helper strain through triparental mating. The recombinant vector having Agrobacterium was infected with tomato leaf discs through cocultivation and the leaf discs were transferred to selection media containing Kanamycin and direct regeneration of the plantlet were obtained from the leaf discs. The npt-II gene (Kanamycin resistance gene) serves as a selectable marker system in plants. The regenerated plantlets grown on selection media was subjected to primary screening by isolating the genomic DNA by CTAB (Cetyl Trimethyl Ammonium Buffer) method and the transformation was confirmed by the presence of amplified fragments of WGA gene by PCR analysis.
\end{abstract}

Key words: A. tumefaciens, E. coli DH5 $\alpha$, Lycopersicon esculentum, npt-II, pGPTV, WGA.

\section{INTRODUCTION}

Tomato is one of the most important vegetable crops worldwide with a total production of around 141 million tons on a cultivated area of 5 million hectares (FAOSTAT, 2009, http://faostato.fao.org) and is attacked by pest and disease leading to loss of about $14 \%$ of the crop yield. Application of the pesticides were the earlier choice and massive application of pesticides results in adverse effects on the beneficial organisms, leaves pesticide residues in the food and results in environmental pollution. As a result, the chemical control of pests is under increasing pressure. Hence as an alternative approach, after centuries of improving crop plants by breeding for desirable traits, agricultural scientists are now using the tools of molecular biology and genetic engineering to develop transgenic plants with the desired genes. Transgenic plants are crops that have been genetically modified with genes from other organism to make the plants commercially more attractive and genetically superior. Tomato was selected as host plant since it exhibits large amount of morphological and chemical 
phenotypic plasticity that appears to be adaptive and it can be easily regenerated in in-vitro conditions [21].

Wheat germ agglutinin (WGA) is a N-acetylglucosamine binding lectin [1] which though maximally synthesized in the developing wheat embryos [31] is also accumulated in the vegetative tissues [16]. Lectins are proteins that recognize and reversibly bind to specific sugar chains of glycosylated molecules (E.g. Polysaccharides, glycoproteins etc.). In wheat, WGA is synthesized in the developing and germinating embryos, roots and meristematic regions of leaves and is not found in the endosperm. Basically $W G A$ is a glycoprotein with very specific carbohydrate binding property and has high affinity towards $\mathrm{N}$-acetyl glucosamine (NAG). They are believed to be "natures own insecticide". Lectins are found to be toxic to insects. Toxic effect appears to be mediated through binding of the lectins to glycoprotein in the insect leading to the disruption of gut epithelial cells. Various lectins with different sugar binding specificities may show selective toxicities. Lectins are found to be toxic to Coleoptera and Lepidoptera [27].

Enormous progress has been made over the past decade in our understanding of the highly complex molecular events that occur in plant-pathogen interactions [2]. Techniques of exogenous gene introduction in plant cells have been actively applied for producing transgenic cultured cells that produce high levels of useful biological substances and are used for the molecular breeding of plants. Genetic engineering techniques now permit the transfer the genes across species. Plant resistance against insects can be achieved by introducing foreign genes which contribute insect resistance. $W G A$ gene can efficiently be used to develop insect resistance in tomato plants. There are various methods for the genetic transformation of the plants like particle bombardment, protoplast fusion but Agrobacterium-mediated gene transfer offers the advantage of specific and stable gene integration.

The gram negative soil bacterium Agrobacterium tumefaciens is a phytopathogen that as a normal part of its lifecycle, genetically transforms plant cells. This genetic transformation leads to the formation of crown gall tumors. Crown gall is the consequence of transfer, integration and expression of genes of a specific segment called the T-DNA which is part of the larger Ti plasmid carried by these bacteria. The Ti plasmid encodes for the vir (virulence) gene products which are required for the transfer and integration of the T-DNA into the plant genome [5]. After a Ti plasmid carrying cell of the A. tumefaciens attaches to the host plant cell and the vir genes are induced, the T-DNA is transferred by the process that is similar to the plasmid transfer from donor to recipient in the bacterial conjugation [25]. The simplest way to exploit the ability of the Ti plasmid to genetically transform plants would be to insert a desired DNA sequence into the TDNA region and then use the Ti plasmid and the A. tumefaciens to deliver and insert this gene into the susceptible plant genome. The Ti plasmid based vectors contain a selectable marker gene, an E. coli origin of replication, right border of the T-DNA which is absolutely required for integration, and a poly linker to facilitate the insertion of the gene into the region between the T-DNA border sequences. Since these cloning vectors lack the vir genes, they cannot by themselves affect the transfer of the T-DNA region into the recipient plants. So a binary vector system that contains both E. coli and A. tumefaciens origin of replication, but no vir genes is used. The recipient $A$. tumefaciens carries a modified Ti plasmid that contains a complete set of vir genes but lacks portions or the entire T-DNA region and so 
this T-DNA cannot be transferred. In this system, the defective Ti plasmid synthesizes the vir gene products that mobilize the T-DNA region of the binary vector. By providing the proteins encoded by the vir genes, the defective Ti plasmid is acting as the helper plasmid enabling the TDNA from the binary vector to be inserted into the plant chromosomal DNA. Since the 1980s several Agrobacterium-mediated transformation protocols have been developed in tomato, using cotyledons or leaves [20, 24, 32].

\section{MATERIALS AND METHODS}

\section{Plant materials and culture conditions}

Tomato seeds were sterilized with $0.1 \% \mathrm{HgCl}_{2}$ for 10 minutes and with $70 \%$ ethanol for 90 seconds. They were soaked in sterile distilled water overnight and the embryos were dissected out and placed on MS [17] basal medium with 0.8\% agar for germination. The plantlets obtained were further propagated such that the explants had at least one axilliary bud or meristem. After four weeks, fully grown healthy shoots were selected for transformation. The incubation conditions for in vitro culture were $25^{\circ} \mathrm{C}$ and $4000 \mathrm{Lux}$ with a photoperiod of 16 hours and $70 \%$ humidity.

\section{Bacterial strains and binary plasmid vectors}

WGA gene present in pUC vector was released by digestion with EcoRI and XbaI. The insert was ligated to the binary vector pGPTV which confers resistance to Kanamycin. E. coli DH5 $\alpha$ cells were transformed with the ligated plasmid and selected on Kanamycin $(100 \mu \mathrm{g} / \mathrm{ml})$ containing Luria Bertani (LB) medium [22]. From the transformed E. coli cells, the plasmid was mobilized into A. tumefaciens strain LBA4404 (having resistance to Rifampicin and streptomycin) with the help of another strain of E. coli harboring the pRK2013 plasmid (helper strain) by the process of triparental mating. The mixed culture of these three strains was incubated on YEP medium containing $1 \%$ peptone, $1 \%$ yeast extract, $0.5 \%$ sodium chloride, bacteriological agar $1.5 \%, \mathrm{pH} 7.0$ for $12-18$ hours at $28^{\circ} \mathrm{C}$. This culture was then serially diluted and plated onto $\mathrm{AB}$ minimal medium containing $50 \mu \mathrm{g} / \mathrm{ml} \mathrm{Kanamycin,} 100 \mu \mathrm{g} / \mathrm{ml}$ Rifampicin and $100 \mu \mathrm{g} / \mathrm{ml}$ streptomycin. $\mathrm{AB}$ medium consists of $\mathrm{AB}$ salts $\left(\mathrm{NH}_{4} \mathrm{Cl} 0.05 \%, \mathrm{CaCl}_{2}\right.$ $0.0075 \%, \mathrm{MgSO}_{4} .7 \mathrm{H}_{2} \mathrm{O} 0.015 \%, \mathrm{FeSO}_{4} .7 \mathrm{H}_{2} \mathrm{O} 0.00125 \%$, KCL $0.0075 \%$ ) and $\mathrm{AB}$ buffer $\left(\mathrm{KH}_{2} \mathrm{PO}_{4} 0.15 \%, \mathrm{NaH}_{2} \mathrm{PO}_{4} 0.05 \%, \mathrm{pH} 7.0\right) .100 \mathrm{ml}$ of the $\mathrm{AB}$ agar medium was prepared by adding $20 \mathrm{ml}$ of $\mathrm{AB}$ salt solution, $20 \mathrm{ml}$ of $\mathrm{AB}$ buffer, $5 \%$ glucose and $1.5 \%$ bacteriological agar. The plates were incubated at $28^{\circ} \mathrm{C}$ for 2 days and observed for colonies.

\section{Plant transformation}

Leaf discs of tomato were incubated for 10 minutes at $28^{0} \mathrm{C}$ with a culture of $5 \times 10^{8}$ cells $/ \mathrm{ml}$ of the A. tumefaciens obtained from the triparental mating. The infected leaf discs were blotted and transferred onto regenerating medium with their upper surfaces in contact with the medium. Regenerating medium contains MS salts along with $2.5 \mathrm{mg} / \mathrm{L} \mathrm{BAP}$ and $0.1 \mathrm{mg} / \mathrm{L}$ of IAA. The leaf discs were incubated for two days in dark and then washed with augmentin $(250 \mu \mathrm{g} / \mathrm{ml})$ and transferred to selection medium (selection medium is regenerating medium containing augmentin $(250 \mu \mathrm{g} / \mathrm{ml})$ and kanamycin $(50 \mu \mathrm{g} / \mathrm{ml})[14]$. 


\section{PCR analysis of transformants}

Genomic DNA was isolated from the transformed in-vitro plantlets using the CTAB method [8]. PCR amplification of neomycin phosphotransferase (npt-II gene) using specific primers used to confirm the transgenic status of the plants. PCR reaction was set up using 50ng of the genomic DNA, $0.3 \mu \mathrm{M}$ of the forward and reverse primers, $10 \mathrm{mM}$ dNTP mix and 1 unit of Taq polymerase in a $50 \mu \mathrm{l}$ reaction volume. The amplification conditions were $94^{\circ} \mathrm{C}$ for $5 \mathrm{~min}, 55^{\circ} \mathrm{C}$ for $1 \mathrm{~min}, 72^{\circ} \mathrm{C}$ for $2 \mathrm{~min}$ and a final extension for $5 \mathrm{~min}$ at $72^{\circ} \mathrm{C}$. The amplifications were performed in Corbett Research Thermal Cycler. The amplified products were analyzed on a $1.5 \%$ agarose gel. DNA from the untransformed plants was used as negative controls.

\section{RESULTS AND DISCSUSSION}

\section{Binary vector}

The WGA gene insert was successfully released from the pUC/WGA vector using EcoRI and $X b a I$ enzymes and was ligated into the linearized pGPTV. High efficiency of ligation was seen with vector with insert vector ratio of 1:2. The efficiency of transformation of the $E$. coli competent cells were found to be $4 \times 10^{5} / \mathrm{ug}$ of pUC DNA. Plasmid was isolated from the $E$. coli / pGPTV-WGA cells were again digested with EcoRI and XbaI to release the insert, in order to confirm the presence of the insert. After triparental mating, the transformants alone grew on the Kanamycin, Rifampicin and Streptomycin medium as the plasmid pGPTV-WGA encodes the Kanamycin resistance gene $n p t$-II while rifampicin and streptomycin resistance is encoded by the genome of the host $A$. tumefaciens (Figure 1).

\section{Plant transformation}

Sterile plantlets were obtained by the germination of the dissected embryos and 4 weeks old cultures were used for transformation. Discs were prepared and infected with A. tumefaciens cultures and placed on the media, co-cultivated in the dark for 48 hours. Curling of leaf discs and shoot formation / direct regeneration of shoots was observed after 3-4 weeks on selection media (Figure 2). Non transformants were discolored and necrotic. The efficiency of transformation of the leaf discs were found to be as high as $90 \%$ compared to other reports [11]. The efficiency of transformation depends on the rate of infection and viability of the tissue. The transformants obtained further produced multiple shoots.

\section{Selection of transformants}

The selection of transformants was done by using selection media (is regenerating medium containing augmentin $(250 \mu \mathrm{g} / \mathrm{ml})$ and kanamycin $(50 \mu \mathrm{g} / \mathrm{ml})$ [14]). The transformed cell are having the plasmid pGPTV-WGA encodes the Kanamycin resistance gene $n p t$-II while rifampicin and streptomycin resistance is encoded by the genome of the host A. tumefaciens. The selection media made to select the transformed cells, since the presence of npt-II gene (Kanamycin resistant), and is used for further analysis.

\section{PCR analysis of transformants}

In order to confirm the transgenic status of the transformants, total genomic DNA from the transformed in-vitro plantlets were isolated and used to amplify the $n p t$-II gene which is also transferred along with the WGA gene, using 22 bases long primers. A $560 \mathrm{bp}$ fragment of the 
$n p t$-II gene was amplified in the transformed plants as well as in the reaction using the plasmid pGPTV/WGA. No amplification was seen in the untransformed plants (Figure 3).

A. tumefaciens mediated gene transfer has been carried out and the success of $A$. tumefaciens mediated plant transformation depends mainly on the specific plant-microbe interactions. The effectiveness of bacterial infection is depends on tissue type, age, genotype, and susceptibility to the microbes. The specific plant-bacteria interactions and the T-DNA transfer process is controlled by vir genes and the initiation of vir genes is dependent upon various factors which include the presence of phenolic compounds, media $\mathrm{pH}$ and temperature [29, 10, 19, 25]. Wounding of the plant tissue releases acetosyringones, which induce the vir genes and make efficient bacterial infection in the plant tissue (leaf discs). Other methods of wounding the tissue include sonication and particle bombardment followed by infection with A. tumefaciens. The plant-bacterial interactions releases of peroxidase enzyme which leads to necrosis of the tissue and is the one of the problems associated with A. tumefaciens mediated plant transformation. Necrosis of the plant tissues can be prevented by including antioxidants in the culture media.

Several different direct DNA transfer methods for plants have been described, including particle bombardment [12, 4], microinjection [6], transformation of protoplasts mediated by polyethylene glycol or calcium phosphate [18], electroporation [26, 9] and transformation using silicon carbide whiskers [7]. A. tumefaciens mediated transfer of DNA is a natural method of transformation of plants and this technology has been used for the production of transgenic tomatoes expressing a variety of heterologous proteins like the beta amyloid protein for vaccine against Alzheimer`s disease and human Factor IX. The transgenic plants obtained in this study will further have to be subjected to field trials to prove their efficacy. The use of A. tumefaciens is less labour intensive, does not require sophisticated equipment and is more cost effective. It aids fast regeneration of the tissues and also allows large amount of the DNA to be transferred to the plant with precise integration. Standardization of an efficient method of gene transfer is therefore of great importance in creating transgenic plants.

Integrated pest management has historically placed great hopes on host plant resistance. However, conventional host-plant resistance to insects involves quantitative traits at several loci. As a result, the progress has been slow and difficult to achieve. With the advent of genetic transformation technique, it has become possible to clone and insert genes into the crop plants to confer resistance to insect pests. Resistance to insect pest has been achieved in transgenic tomato plants expressing WGA gene. The present rate of increasing pollution, population and poverty leads to the need of using biotechnological tools for crop improvement for providing resistance to insect pests. It is equally important that the need to follow the biosafety regulations and make this technology available to farmers, who cannot afford the high cost of agricultural practices. 


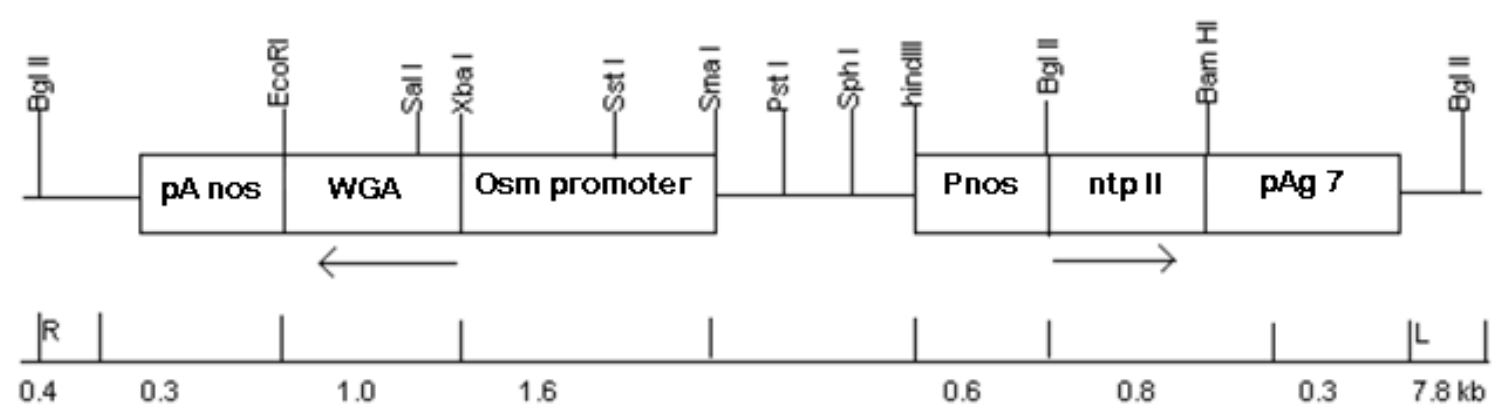

Figure 1. Schematic representation of T-DNA of binary vector pGPTV/WGA
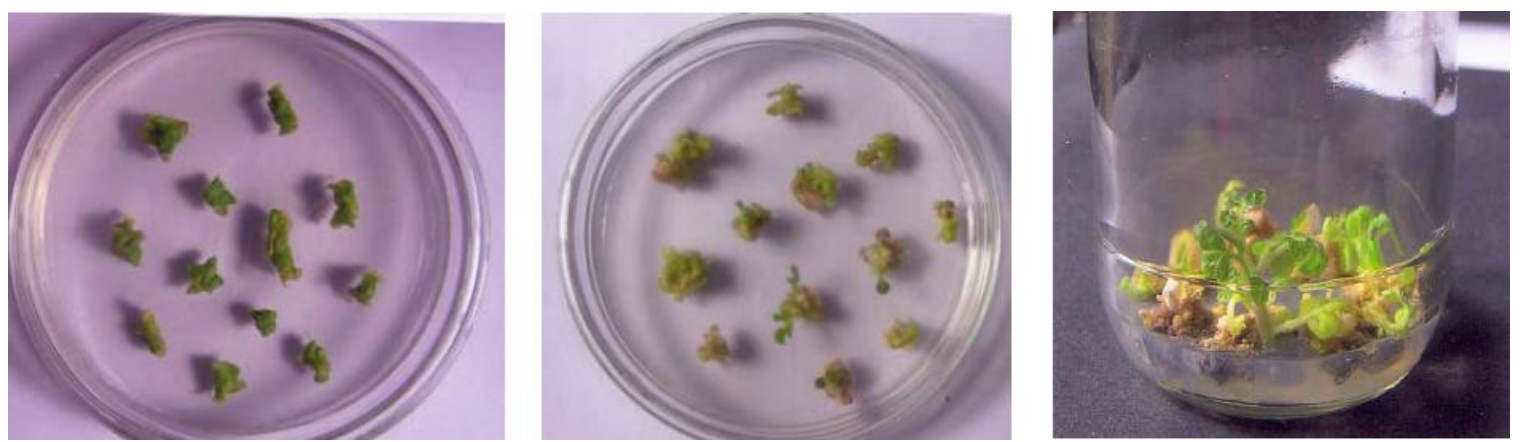

Figure 2. Stages in development of transformed plantlets. Curled leaf discs showing response (b) Direct regeneration of the explants (c) Growth of the plantlets

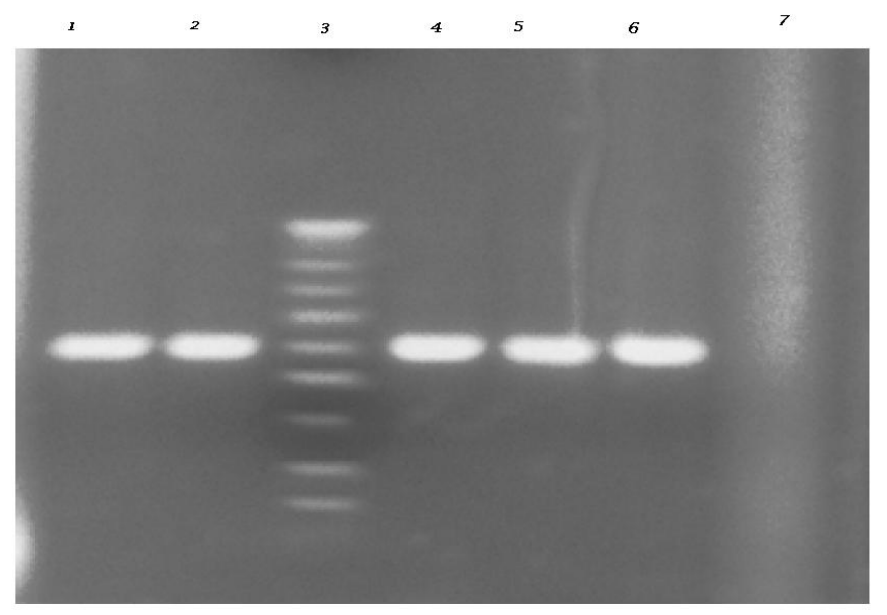

Figure 3. PCR analysis of 560bp fragment of $n p t$-II gene. Lane 1- plasmid pGPTV / WGA, lanes, 2, 4, 5, 6-transformed plants, lane 3-100bp ladder, Lanes 7-untransformed plant. 


\section{REFERENCES}

[1] Allen AK, Neuberger A and Sharon N. The purification, composition and specificity of wheat germ agglutinin, Biochemical J 131 (1973): 155-162.

[2] Anita Grover and R. Gowthaman. Strategies for development of fungus-resistant transgenic plants, Current Science, 84 (2003), 3.

[3] Christou, P., Ford. T.L., Kofron. M. Rice genetic engineering: A review, Trends in Biotechnology, 10 (1992): 239-246.

[4] Close T.J. Dual control of Agrobacterium tumefaciens Ti plasmid virulence genes, J. Bacteriol. 169(11) (1987):5113-5118.

[5] Crossway. A., Oakes.J.V, Irvine.J.M, Ward.B., Knauf. V.C., Shewmaker.C.K. 1986. Integration of foreign DNA following microinjection of tobacco mesophyll protoplasts, Molecular \& General Genetics, 202 (1987): 179185,

[6] Datta, S.K.; Peterhans, A.; Datta, K.; Potrykus, I. Genetically engineered fertile Indicarice plants recovered from protoplasts. Bio/Technology, 8 (1990): 736-740.

[7] Doyle JJ and Doyle JL, Isolation of plant DNA from fresh tissue. Focus, 12 (1990), 1: $13-15$.

[8] Frame, B.R., Drayton, P.R., Bagnall, S.V., Lewnau, C.J., Bullock, W.P., Wilson, H.M., Dunwell, J.M., Thompson, J.A., Wang, K. Production of fertile transgenic maize plants by silicon-carbide whisker-mediated transformation. Plant Journal, 6 (1994): 941-948.

[9] Godwin, I., Todd, G., Ford-Loyd, B., Newbury, H.I. The effects of acetosyringone and $\mathrm{pH}$ on Agrobacterium mediated transformation vary according to plant species. Plant Cell Reports, 9 (1991): 671-675.

[10] Hamza S, Reevaluation for conditions for plant regeneration and Agrobacterium mediated transformation from tomato, J. Exp. Bot, 44 (1993), 12: 1837-1845.

[11] Klein TM, Wolf ED, Wu R, Sanford JC. Hugh-velocity microprojectiles for delivering nucleic acids into living cells. Nature, 327 (1987):70-3.

[12] McCormick. Leaf Discs transformation of cultivated tomato (Lycopersicon esculentum L) using Agrobacterium tumefaciens. Plant Cell Rep, 5 (1986): 81-84.

[13] Mishkind ML, Keegstra K and Palevitz BA. Distribution of wheat germ agglutinin in young wheat plants. Plant Physiol., 66 (1980): 950-955

[14] Murashige T and Skoog F. A revised medium for rapid growth and bioassays with tobacco tissue culture; Physiol.Plant., 15 (1962): 473-497. 
[15] Negrutiu I, Shillito R, Potrykus I, Biasini G, Sala F. Hybrid genes in the analysis of transformation conditions. Plant Mol Biol., 8 (1987): 363-373

[16] Nordlee, J.A., S.L. Taylor, J.A. Townsend, L.A. Thomas, and R.K Bush. "Identification of a Brazil nut allergen in transgenic soybeans. New England Journal of Medicine 334 (1993): 688-92.

[17] Pino, L.E.; Lombardi-Crestana, S.; Azevedo, M.S.; Scotton, D.C.; Borgo, L.; Quecini, V.; Figueira, A. \& Peres, L.E.P. The Rg1 allele as a valuable tool for genetic transformation of the tomato "Micro-Tom" model system. Plant Methods, 6 (2010):23

[18] Preston CA, Lewandowski C, Enyedi AJ \& Baldwin IT. Tobacco mosaic virus inoculation inhibits wound-induced jasmonic acid-mediated responses within but not between plants. Planta 209 (1999): 87-95.

[19] Sambrook, J. Molecular Cloning a laboratory manual, Cold Spring Harbor Laboratory Press, New York, 2 (1989).

[20] Sharma, M.K.; Solanke, A.U.; Jani, D.; Singh, Y.; Sharma, A.K. A simple and efficient Agrobacterium-mediated procedure for transformation of tomato, Journal of Biosciences, 34 (2009), 3: 423-433

[21] Sheng, J.; Citovsky, V. Agrobacterium-Plant cell DNA transport: have virulence proteins, will travel. The Plant Cell, 8 (1996): 1699-1710.

[22] Shillito, R.D., Saul, M.W., Müller, M., Paszkowski, J. and Potrykus, I. High efficiency direct gene transfer to plants, Bio/Technology 3 (1985): 1099-1103.

[23] Shukle R.H. and Murdock L.L. Lipoxygenase, trypsin inhibitor, and lectin from soybean: effects on larval growth of Manduca sexta (Lepidoptera:Sphingidae). Environmental Entomology, 12 (1983): 787-791.

[24] Statchel, S.E.; Messens, E.; Montagu, M. van; Zambryski, P. Identification of the signal molecules produced by wounded plant cells that activate T-DNA transfer in Agrobacterium tumefaciens. Nature, 318 (1985): 624-629.

[25] Triplett B.A. and Quatrano R.S. Timing, localization and control of wheat germ agglutinin synthesis in developing wheat embryos, Dev. Biol., 91 (1982): 491-49

[26] Van Eck, J.; Kirk, D.D. \& Walsmley, A.M. Tomato (Lycopersicum esculentum). Methods in Molecular Biology, 343 (2006): 459-4773. 